\section{Limitations of traditional morphometrics in research on the attractiveness of faces}

\author{
Erik Holland \\ www.femininebeauty.info
}

The traditional morphometrics approach to shape comparisons involves computing multiple interlandmark distances without taking into account the geometric configuration of the landmarks. A recent example of this approach is a study by Potter and Corneille (2008). They had participants rate the attractiveness of computer-generated European, African, and Asian male faces, and they computed the Euclidean distances between each face and the group prototypes. They found that faces are rated more attractive when they are closer to their group prototype. This letter addresses differing conclusions in the literature, the methodological shortcomings of Potter and Corneille, and another study that explored a similar topic, with a special focus on guiding future researchers around the pitfalls of traditional morphometrics.

\section{Conclusions Different From \\ Potter and Corneille's (2008)}

In many non-European populations, the attractive face is less ethnic-looking and closer to European norms than the average. This has been documented for KoreanAmerican women evaluated by their co-ethnics (Choe, Sclafani, Litner, Yu, \& Romo, 2004) and also for the profile of African-Americans (Farrow, Zarrinnia, \& Azizi, 1993; Martin, 1964; Polk et al., 1995; Sushner, 1977; Thomas, 1979; but see Sutter \& Turley, 1998, for a null find). Aesthetic facial cosmetic surgeries in East Asians (Ahn, 2006; Dobke, Chung, \& Takabe, 2006; Lam, 2005) and African-Americans (Rohrich \& Muzaffar, 2003) also tend to cluster in the direction of European norms.

Rhodes et al. (2005) found that Eurasian faces obtained by morphing European and East Asian faces were rated more attractive than European or East Asian faces. To my knowledge, this is the only study that has documented a shift toward East Asian norms increasing the perceived attractiveness of European faces, but this study had numerous shortcomings. These authors had the participants rate composite face morphs, rather than individual faces, for attractiveness. Some adjustments for differences in face size need to be performed when morphing faces together: A common practice, also employed by Rhodes et al., is to equalize interpupillary distance. However, a single interlandmark distance is a poor approximation of face size. In one standard implementation for controlling for size, one computes the center of mass of a form with unit mass at each of its landmarks. This is known as the centroid. One obtains the centroid size by summing the squared dis- tances of a form's landmarks from its centroid. Then, scaling all forms to the same centroid size adjusts for size.

Another problem with Rhodes et al. (2005) is that all groups of the faces used (European, Asian) should have had similar distributions of attractiveness and femininity with respect to the norms in the respective ethnic groups. This is because the average of attractive faces is rated more attractive than the average of nonattractive faces (Johnston \& Oliver-Rodriguez, 1997; Perrett, May, \& Yoshikawa, 1994), and the femininity of a woman's face is a much more powerful correlate of beauty than its prototypicality (Rhodes, 2006); the prototypical female face is at the 50th percentile of femininity among women. But we have no indications that these requirements are met in Rhodes et al., and they would be difficult to fulfill.

Yet another problem with Rhodes et al. (2005) is that when one uses face composites, one cannot readily assess the effect on attractiveness when faces across a range of attractiveness are transformed along ethnic lines. Furthermore, Rhodes et al. assumed face shapes of ethnically mixed offspring to be an average of the parental face shapes, but this is not true for the majority of face-shape variables (Martínez-Abadías et al., 2006).

\section{Methodological Issues}

Faces generated by FaceGen Modeller. Potter and Corneille (2008) generated faces using FaceGen Modeller (www.facegen.com). FaceGen is mainly used by game developers. It is also used by police to generate 3-D sketches of suspects. However, there are concerns about how well FaceGen parallels reality. In comparison with European faces, the nasion is displaced inferiorly in subSaharan Africans (Africans) and East Asians (Hennessy \& Stringer, 2002), but FaceGen achieves this effect primarily by raising the eyebrows in Africans and Asians, not by lowering the nasion. The flattest nasal bones are found in sub-Saharan African populations (Hanihara, 2000), but FaceGen makes East Asian nasals flatter than African nasals. Europeans tend to have shorter chins than Africans and East Asians (Bastir, Rosas, \& Kuroe, 2004), but not so in FaceGen. These limitations are of little relevance to game developers or police because these groups need only to generate faces that approximate target faces. Also, FaceGen can be used as a very basic educational tool, but psychological research is another matter. If the research addresses basic perceptions of ethnicity, sex differences, or attractiveness and involves no facial measurements, then FaceGen can be used for convenience; but when minutiae of shape variables and measurements are involved, it is best to use actual faces.

Variation between and within populations. Most skull shape variation in humans lies within populations (Roseman \& Weaver, 2004). Because there is a correlation 
structure underlying differences between populations, geographical clusters appear with the assessment of multiple interlandmark craniofacial distances (Brace \& Hunt, $1990)$ or the geometric configuration of the landmarks (Hennessy \& Stringer, 2002). Nevertheless, there also is clinal variation (Hanihara, 1996, 2000). Hence, with representative sampling of a population, it should be possible to obtain faces that represent variation within this population, as well as faces somewhat shifted toward the norms of other populations on multiple counts.

To investigate whether facial attractiveness varies along the discriminant distinguishing ethnic groups, this component must be isolated from total face shape variation. However, Rhodes et al. (2005) could not do this and, hence, did not address the extent to which the higher attractiveness of Eurasian faces resulted from variation along the discriminant distinguishing European from Asian faces, rather than from other shape components. Potter and Corneille (2008) used the "rand lock" feature in FaceGen, which keeps dimensions that are key to a group constant, to generate random faces for each population. It is questionable how well FaceGen achieves this. If it does so well, the authors did not have faces within a group that varied among themselves along the discriminant distinguishing this group from other groups and, hence, could not answer how attractiveness varies as a function of distance from other-group prototypes. Even if FaceGen Modeller had produced random faces within a group, so that a few faces were, overall, somewhat shifted toward other-group norms, then the authors would still have needed to control for the within-population variation component in order to answer their chief question.

Confounds between sexual dimorphism and ethnicity. In a sample of 29 human populations with 28 known craniofacial measurements, the average distance between populations (percentage difference per size-corrected measurement) was about 10 times greater than the average distance between the sexes within populations (Sarich \& Miele, 2004). Therefore, face shape differences across the major ethnic groups are predominantly associated with factors apart from sex hormones and other contributors to sexual dimorphism. Some interpopulation differences are in a roughly similar direction as sex differences. For instance, Europeans have more prominent nasal bones than those of non-Europeans, but so do men, as compared with women. Similarly, non-Europeans have less angular faces than those of Europeans, but so do women, as compared with men. Therefore, when considering face shape transformation along ethnic lines, how can one determine whether, say, a preference for less angular features is a preference for reduced masculinization or increased non-Europeanization? Sexual dimorphism must be controlled for in such studies.

\section{Suggestions for Future Studies}

The best set of statistical tools for analyzing shape and regressing shape components against variables of interest, such as attractiveness ratings, is geometric morphometrics (Bookstein, 1996; O'Higgins, 2000). Traditional morphometrics ignores the geometric configuration of the landmarks used for assessing interlandmark distances.
Geometric morphometrics captures information about the geometric configuration of the landmarks by assessing a shape in terms of its landmark coordinates and allows us to define shape as a single point in $n$-dimensional space, conveniently allowing multivariate analyses of shape components and rigorous visualization of shape differences. In this shape space, the shape component or axis joining the consensus shape of an ethnic group to the consensus shape of another ethnic group will be unaffected by within-population variation and sexual dimorphism. Regression analysis can then be used to assess whether attractiveness varies along the axis.

An example of the utility of geometric morphometrics is a shape analysis of European women's face profiles, from which three correlates of attractiveness were extracted: averageness, above-average femininity, and a third element that the authors were unable to interpret (Valenzano, Mennucci, Tartarelli, \& Cellerino, 2006). The jaw shape variables corresponding to the third element were previously documented in studies using composite face morphs (Johnston \& Franklin, 1993; Perrett et al., 1998) and were assumed to be a sex hormone signal (Johnston \& Franklin, 1993), but the third element did not contribute to sexual dimorphism, even though many individual shape shifts associated with the third element have been shown to be affected by sexual dimorphism (Rosas \& Bastir, 2002). Thus, a shape component altering some parts of the face in the same direction as sexual dimorphism, but not displaying the correlation structure underlying shape transformation resulting from sexual dimorphism, will be easily distinguished from sexual dimorphism if the morphometric tool takes into account the geometric configuration of the landmarks.

The third element was predominantly associated with shifts that increased attractiveness in the jaw - a shorter but more prominent chin, a regressed mouth (reduced alveolar prognathism), and a more angled jaw — and also with shifts toward slightly more prominent nasal bones. The third element thus corresponded to shifting the faces of European women away from East Asian norms (Choe et al., 2004), rather than toward it, and this was observed throughout the range of European faces used, whereas the Rhodes et al. (2005) approach at best informs us about the attractiveness of the ethnic transformation of a particular (composite) face. Whereas Valenzano et al. (2006) used face profiles, they reported a strong correlation between frontal and profile attractiveness (Pearson's $r=.66, p<.0001$ ).

How may one interpret the third element? A more angled jaw would have a more defined outline than a hyperfeminine jawline (approximating a curve). The other shifts are in the direction that discriminates humans from ancestral hominids, and aesthetic preferences lying along the ancestral-to-derived discriminant have been documented in both the face and the body (Magro, 1997, 1999). This brings us to the interpretation of the literature that documents a shift toward European norms in attractive nonEuropean faces and is, therefore, discordant with Potter and Corneille (2008). A convenient explanation is the economic domination of Western societies and the strong global presence of Western culture. However, northern 
European slaves were admired for their looks in Rome (Pitman, 2003), suggesting that desirable looks are not necessarily associated with the socioeconomic elite. The alternative explanation is that there is a preference for somewhat more overall derived facial features in humans, which parallels a shift toward European norms because Europeans have more overall derived faces (Hanihara, 2000). Thus, European cultural hegemony does not necessarily fully account for why attractive non-European faces are shifted toward European norms. Further research on this topic will potentially be better if actual faces and geometric morphometrics are used. The actual faces can be presented in the form of photographs or, better still, photogrammetric or laser scans of faces for 3-D assessments.

\section{AUTHOR NOTE}

Correspondence concerning this article should be addressed to E. Holland, P.O. Box 2994, Tempe, AZ 85280 (www.femininebeauty.info; e-mail: fbeauty_webmaster@yahoo.com).

\section{REFERENCES}

AhN, J. M. (2006). The current trend in augmentation rhinoplasty. Facial Plastic Surgery, 22, 61-69.

Bastir, M., Rosas, A., \& Kuroe, K. (2004). Petrosal orientation and mandibular ramus breadth: Evidence for an integrated petrosomandibular developmental unit. American Journal of Physical Anthropology, 123, 340-350.

BooksteIn, F. L. (1996). Biometrics, biomathematics and the morphometric synthesis. Bulletin of Mathematical Biology, 58, 313-365.

BRACE, C. L., \& Hunt, K. D. (1990). A nonracial craniofacial perspective on human variation: A(ustralia) to Z(uni). American Journal of Physical Anthropology, 82, 341-360.

Choe, K. S., Sclafani, A. P., Litner, J. A., Yu, G.-P., \& Romo, T., III (2004). The Korean American woman's face: Anthropometric measurements and quantitative analysis of facial aesthetics. Archives of Facial Plastic Surgery, 6, 244-252.

Dobke, M., Chung, C., \& Takabe, K. (2006). Facial aesthetic preferences among Asian women: Are all oriental Asians the same? Aesthetic Plastic Surgery, 30, 342-347.

FARrow, A. L., ZarrinNIA, K., \& AZIZI, K. (1993). Bimaxillary protrusion in black Americans-An esthetic evaluation and the treatment considerations. American Journal of Orthodontics \& Dentofacial Orthopedics, 104, 240-250.

Hanihara, T. (1996). Comparison of craniofacial features of major human groups. American Journal of Physical Anthropology, 99, 389412.

Hanihara, T. (2000). Frontal and facial flatness of major human populations. American Journal of Physical Anthropology, 111, 105-134.

Hennessy, R. J., \& Stringer, C. B. (2002). Geometric morphometric study of the regional variation of modern human craniofacial form. American Journal of Physical Anthropology, 117, 37-48.

Johnston, V. S., \& FrankLIN, M. (1993). Is beauty in the eye of the beholder? Ethology \& Sociobiology, 14, 183-199.

Johnston, V. S., \& Oliver-Rodriguez, J. C. (1997). Facial beauty and the late positive component of event-related potentials. Journal of Sex Research, 34, 188-198.
LAM, S. M. (2005). Aesthetic facial surgery for the Asian male. Facial Plastic Surgery, 21, 317-323.

Magro, A. M. (1997). Why Barbie is perceived as beautiful. Perceptual \& Motor Skills, 85, 363-374.

Magro, A. M. (1999). Evolutionary-derived anatomical characteristics and universal attractiveness. Perceptual \& Motor Skills, 88, 147-166.

Martin, J. G. (1964). Racial ethnocentrism and judgment of beauty. Journal of Social Psychology, 63, 59-63.

Martínez-Abadías, N., GonZález-José, R., GonZález-Martín, A., Van der Molen, S., Talavera, A., Hernández, P., \& HernánDEZ, M. (2006). Phenotypic evolution of human craniofacial morphology after admixture: A geometric morphometrics approach. American Journal of Physical Anthropology, 129, 387-398.

O'Higgins, P. (2000). The study of morphological variation in the hominid fossil record: Biology, landmarks and geometry. Journal of Anatomy, 197, 103-120.

Perrett, D. I., Lee, K. J., Penton-Voak, I., Rowland, D., YoshiKAWA, S., BURT, D. M., ET AL. (1998). Effects of sexual dimorphism on facial attractiveness. Nature, 394, 884-887.

Perrett, D. I., May, K. A., \& Yoshikawa, S. (1994). Facial shape and judgements of female attractiveness. Nature, 368, 239-242.

Pitman, J. (2003). On blondes. London: Bloomsbury.

Polk, M. S., JR., Farman, A. G., Yancey, J. A., Gholston, L. R., JohnSON, B. E., \& REgEnNitTer, F. J. (1995). Soft tissue profile: A survey of African-American preference. American Journal of Orthodontics \& Dentofacial Orthopedics, 108, 90-101.

PotTer, T., \& CoRneILle, O. (2008). Locating attractiveness in the face space: Faces are more attractive when closer to their group prototype. Psychonomic Bulletin \& Review, 15, 615-622.

RHODES, G. (2006). The evolutionary psychology of facial beauty. Annual Review of Psychology, 57, 199-226.

Rhodes, G., Lee, K., Palermo, R., Weiss, M., Yoshikawa, S., Clissa, P., ET AL. (2005). Attractiveness of own-race, other-race, and mixed-race faces. Perception, 34, 319-340.

Rohrich, R. J., \& MuzafFar, A. R. (2003). Rhinoplasty in the AfricanAmerican patient. Plastic \& Reconstructive Surgery, 111, 1322-1339.

Rosas, A., \& BastiR, M. (2002). Thin-plate spline analysis of allometry and sexual dimorphism in the human craniofacial complex. American Journal of Physical Anthropology, 117, 236-245.

Roseman, C. C., \& Weaver, T. D. (2004). Multivariate apportionment of global human craniometric diversity. American Journal of Physical Anthropology, 125, 257-263.

SARICH, V., \& Miele, F. (2004). Race: The reality of human differences. Boulder, CO: Westview Press.

Sushner, N. I. (1977). A photographic study of the soft-tissue profile of the Negro population. American Journal of Orthodontics, 72, 373385.

Sutter, R. E., JR., \& Turley, P. K. (1998). Soft tissue evaluation of contemporary Caucasian and African American female facial profiles. Angle Orthodontist, 68, 487-496.

Thomas, R. G. (1979). An evaluation of the soft-tissue facial profile in the North American black woman. American Journal of Orthodontics, 76, 84-94.

Valenzano, D. R., Mennucci, A., Tartarelli, G., \& Cellerino, A. (2006). Shape analysis of female facial attractiveness. Vision Research, 46, 1282-1291.

(Manuscript received July 16, 2008;

revision accepted for publication February 5, 2009.) 